\title{
EFFECT OF ADSORBED POLYANILINE ON THE THERMAL STABILITY OF IRON AND ARSENIC OXIDES
}

\author{
Robson Fernandes de Farias \\ Departamento de Química - Universidade Federal de Roraima - UFRR - 69310-270 - Boa Vista - RO
}

Recebido em 9/3/99; aceito em 21/10/99

\begin{abstract}
Iron and arsenic oxide grains are coated with the conducting organic polymer polyaniline. The obtained samples were characterized by infrared spectroscopy, SEM, conducting measurements and thermogravimetry. The thermal stability of both oxides are increased. For $\mathrm{As}_{2} \mathrm{O}_{3}$ the sublimation temperature is increased from $165^{\circ} \mathrm{C}$ in the pure oxide to $206^{\circ} \mathrm{C}$ in the polymer modified sample. The pure $\mathrm{Fe}_{3} \mathrm{O}_{4}$ sample exhibits sublimation at $780^{\circ} \mathrm{C}$ whereas the polyaniline coated oxide is stable until at least $1000^{\circ} \mathrm{C}$.
\end{abstract}

Keywords: polyaniline; thermal degradation; oxide.

\section{INTRODUCTION}

Polyaniline (PANI) is one of the most studied conducting polymers, not only due the facility in preparation procedures, but also related to high stability to the environmental exposition. The normal polimerization to prepare polyaniline has an enthalpy value of $439 \mathrm{~kJ} \mathrm{~mol}^{-1}$ for the emeraldine form $^{1}$, and its protonation (doping) ${ }^{2}$ and many other physicalchemical properties are connected to the presence of the NH- group ${ }^{3}$.

A great number of polymers, such as those derivative of polyaniline or other having some electroactive properties can be inserted into inorganic 2D, 3D or porous host solids ${ }^{4-6}$ as phosphonates $^{7-8}$, phosphates ${ }^{9-11}$, sulfides ${ }^{12}$ and oxides ${ }^{13-15}$, displaying the so called nanocomposites ${ }^{16-21}$, which have enhanced their uncommon electrical properties.

Since polyaniline has characteristic photocatalytical properties $^{22}$, having a conducting band in the visible region which is activated by solar radiation ${ }^{23}$, some kind of synergic relationship could arise when PANI is used as part of a organic/ inorganic mixed material. In this direction, inorganic matrices such many metal oxides, which exhibit a very wide range of electrical resistivity ${ }^{24}$ with catalytical ${ }^{25}$ or photocatalytical properties ${ }^{26,27}$ have been explored. For this purpose, deposition of a layer, or layers of polyaniline on the oxide surface, which polymer is used as a contact interface between oxide and another chemical species and/or electrode surfaces, could exert interesting and important effects on the oxidation-reduction properties of the substrate.

Recently, polyaniline adsorbed on $\mathrm{MoO}_{3}$ was used to electrocatalyse the oxidation of molybdate ion, enhancing several times the electrode responce, and so, can be used as a selective electrode for molybdenum ${ }^{28}$. The effects of polyaniline on redox process on $\mathrm{As}_{2} \mathrm{O}_{3}$ were also studied ${ }^{29}$.

The aim of this work is to study the effects of adsorbed polyanile on the thermal degradation process for iron and arsenic oxides in an attempting to stablish a experimental procedure that allows use this oxides at higher temperatures than the usual ones.

\section{EXPERIMENTAL}

Polyaniline was chemically obtained ${ }^{30}$, by using a $0.50 \mathrm{~mol}$ $\mathrm{dm}^{-3}$ solution of bidistilled anyline (Aldrich) in $1.0 \mathrm{~mol} \mathrm{dm}^{-3}$

e-mail: defarias@uol.com.br
$\mathrm{HCl}$ (Aldrich) as starting materials. To this solution mantained at $278 \mathrm{~K}$ was added, dropwise for $2 \mathrm{~h}, 100 \mathrm{~cm}^{3}$ of a $0.80 \mathrm{~mol}$ $\mathrm{dm}^{3}$ of $\left(\mathrm{NH}_{4}\right)_{2} \mathrm{~S}_{2} \mathrm{O}_{8}$ solution. After the complete addition of the oxidant solution, the mixture was stirred for $10 \mathrm{~h}$, until finished the polymerization. The final polymer, was washed several times with distilled water and acetonitrile, to remove oligomers as well another possible impurities. The obtained polyaniline

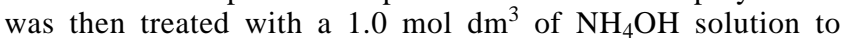
promote deprotonation.

In the next stage, $0.40 \mathrm{~g}$ of the prepared polyaniline was dissolved in $45.0 \mathrm{~cm}^{3}$ of N,N' dimethylformamide (Merck). This solution was added to $2.0 \mathrm{~g}$ of $\mathrm{As}_{2} \mathrm{O}_{3}(99,9 \%$, Carlo Erba) and $0.50 \mathrm{~cm}^{3}$ of $\mathrm{H}_{3} \mathrm{PO}_{4}$ to promote the doping ${ }^{2}$. The mixture was aged for $48 \mathrm{~h}$ at room temperature, before withdrawing the excess of solution and dried at $363 \mathrm{~K}$ overnight. The green powder product containing polyaniline adsorbed on oxide $\mathrm{As}_{2} \mathrm{O}_{3}$ is named from here as $\mathrm{As}_{2} \mathrm{O}_{3}$.pani. A similar procedure was used to prepare a polyaniline coated $\mathrm{Fe}_{3} \mathrm{O}_{4}$ sample, producing $\mathrm{Fe}_{3} \mathrm{O}_{4}$.pani.

The pure and polymer coated samples were characterized by FR-IR in a Bomem apparatus, with pressed $\mathrm{KBr}$ pellets and 25 scans, TG in a Shimadzu TGA-50 under argon atmosphere with heating rate of $8.3 \times 10^{-2} \mathrm{Ks}^{-1}$. The SEM images were obtained in a Jeol, JSM T-300 apparatus, using an accelerating voltage of $15 \mathrm{kV}$. Conductance measurements were taken in a four probe apparatus, using pressed sample discs. No success was achieved in the attempting to obtain ${ }^{13} \mathrm{C} \mathrm{CP}$-MAS spectra for oxide-polyaniline samples.

\section{RESULTS AND DISCUSSION}

In comparing the infrared spectra of PANI in Figure 1 with that for $\mathrm{As}_{2} \mathrm{O}_{3}$ and $\mathrm{As}_{2} \mathrm{O}_{3}$.pani as shown in Figures 3 (a) and (b), the spectra of $\mathrm{As}_{2} \mathrm{O}_{3}$.pani shows three bands, which could be assinged as derived from pani bands: at 579 $\mathrm{cm}^{-1}, 1146 \mathrm{~cm}^{-1}$ and $1255 \mathrm{~cm}^{-1}$. In an attempting to assign the last two bands can be associated to those located in free pani at $1140 \mathrm{~cm}^{-1}$ and $1301 \mathrm{~cm}^{-1}$, respectively, which are usually attributed to the doping process ${ }^{1}$. However, the band at $579 \mathrm{~cm}^{-1}$ has not a clear attribution. For $\mathrm{Fe}_{3} \mathrm{O}_{4}$ and $\mathrm{Fe}_{3} \mathrm{O}_{4}$.pani samples (Figure 2), a broad peak at $1088 \mathrm{~cm}^{-1}$ which could be associated with the free band at $1140 \mathrm{~cm}^{-1}$ in free polyaniline is observed. Emeraldine has two types of basic sites capable of coordinating Lewis acids: amine and imine nitrogens. In the polymer chain they are present in equal numbers. As observed for Lewis acid doped polyaniline ${ }^{31}$, both types of sites could be involved in the interaction (coordination) process. 


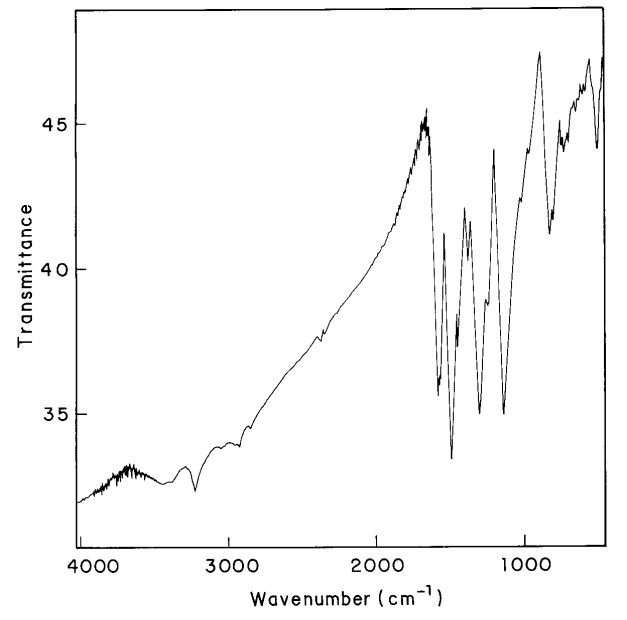

Figure 1. Infrated spectra of plyaniline.

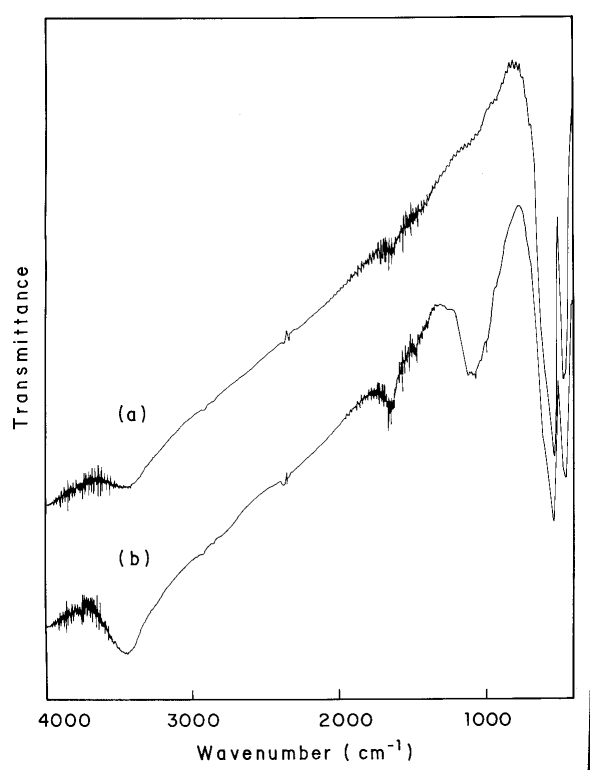

Figure 2. Infrated spectra of (a) $\mathrm{Fe}_{3} \mathrm{O}_{4}$ and (b) $\mathrm{Fe}_{3} \mathrm{O}_{4}$.pani.

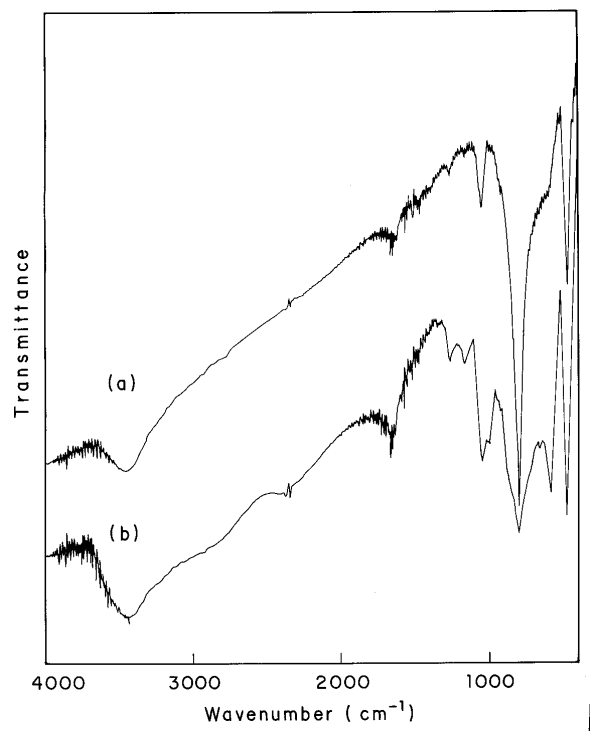

Figure 3. Infrated spectra of (a) $\mathrm{As}_{2} \mathrm{O}_{3}$ and (b) $\mathrm{As}_{2} \mathrm{O}_{3}$.pani.
The SEM micrographs for the pure and polymer oxide samples are shown in figures 4 and 5 . As can be noted, mainly to arsenic oxide, the polymer are adsorbed on the grains surface.
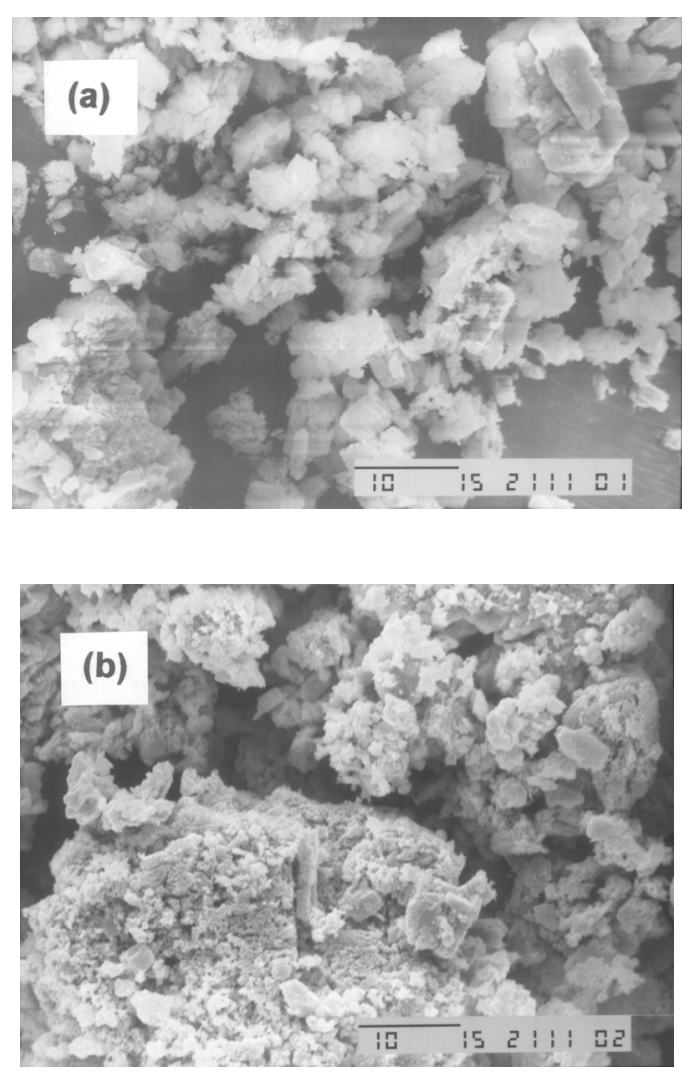

Figure 4. SEM micrographs of (a) $\mathrm{Fe}_{3} \mathrm{O}_{4}$ and (b) $\mathrm{Fe}_{3} \mathrm{O}_{4}$.pani.
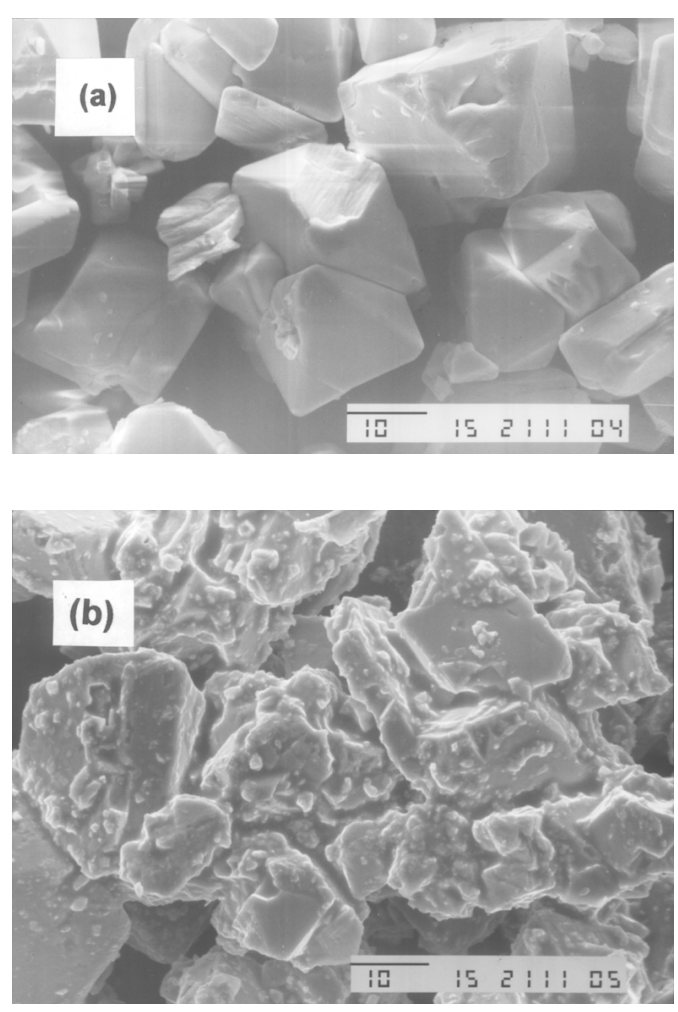

Figure 5. SEM micrographs of (a) $\mathrm{As}_{2} \mathrm{O}_{3}$ and (b) $\mathrm{As}_{2} \mathrm{O}_{3}$.pani. 
The conductivity of pellets obtained by pressing powders are $3.4 \times 10^{-4} \Omega^{-1} \mathrm{~cm}^{-1}$ and $34.2 \times 10^{-4} \Omega^{-1} \mathrm{~cm}^{-1}$, for $\mathrm{As}_{2} \mathrm{O}_{3}$ and $\mathrm{As}_{2} \mathrm{O}_{3}$ :pani, respectively. These values indicated that the material with polyaniline has a conductivity, which is about ten times larger than that of the pure oxide. This result coroborated that the polymer deposition occurred on the substrate surface.

The termogravimetric curve of $\mathrm{As}_{2} \mathrm{O}_{3}$ presents a total mass lost due to the sublimation of the oxide, whereas the TG curve of $\mathrm{As}_{2} \mathrm{O}_{3}$.pani shows a first mass loss step of $87 \%$ due to oxide sublimation and a second one of $13 \%$, due to the thermal degradation of the organic moiety. The second mass loss step exhibits a profile consistent with the thermal degradation of emeraldine ${ }^{32-33}$. Thermogravimetric technique can be considered as a reliable tool to characterize solid surfaces ${ }^{34,35}$, and then, the fraction of $13 \%$ can be assumed as been the total amount of deposition of polyaniline on $\mathrm{As}_{2} \mathrm{O}_{3}$ surface.

For $\mathrm{Fe}_{3} \mathrm{O}_{4}$.pani a mass loss of $11 \%$ can be observed due to the release of polyaniline molecules. So, for both oxides the total amount of adsorbed polyanilne is almost the same.

For both oxides an increase in the thermal stability was observed since the sublimation temperature of arsenic oxide is about $165^{\circ} \mathrm{C}$ for the pure oxide and $206^{\circ} \mathrm{C}$ for the polymer modified one. The pure iron oxide sample used sublimates at $780^{\circ} \mathrm{C}$ whereas the polyaniline modified sample do not sublimate until the maximum temperature used, $1000^{\circ} \mathrm{C}$.

The reasons to the observed phenomena could be atributed to the interaction of nitrogen atoms or $\pi$ electrons of the aromatic rings of polyaniline with the acidic sites in the oxides surfaces, with polyaniline coating sheets acting as a "thermal barrier", since it absorbs the heat transfered to the polymer coated samples.

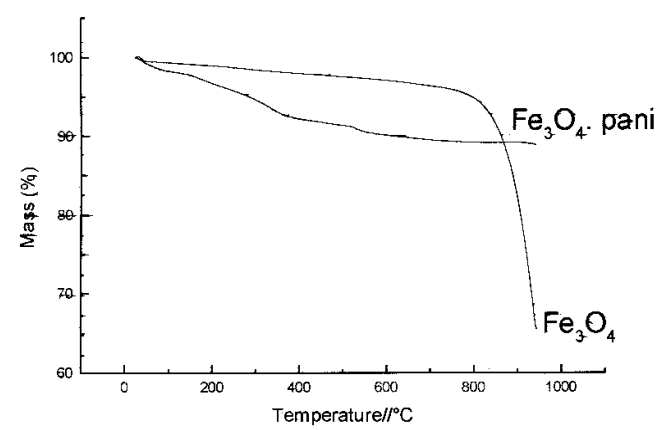

Figure 6. Thermogravimetric curves of $\mathrm{Fe}_{3} \mathrm{O}_{4}$ and $\mathrm{Fe}_{3} \mathrm{O}_{4}$.pani.

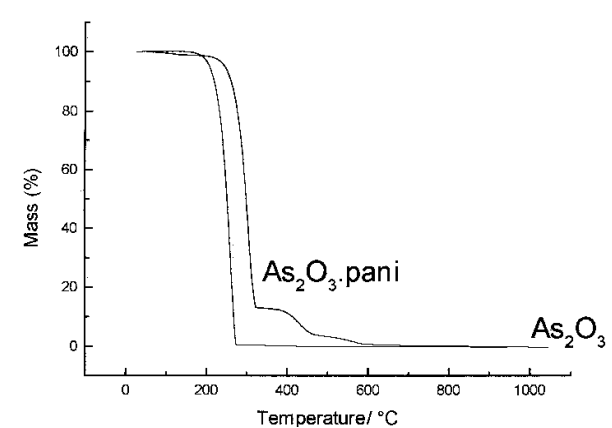

Figure 7. Thermogravimetric curves of $\mathrm{As}_{2} \mathrm{O}_{3}$ and $\mathrm{As}_{2} \mathrm{O}_{3}$.pani.

\section{CONCLUSION}

The obtained experimental results shows that polyaniline can be used to increase the thermal stability of iron and arsenic oxides. Since polyaniline, as well as many metal oxides exhibit electrical and catalytic properties, an increase in thermal stability could be an desirable improvement in such organicinorganic materials.

\section{REFERENCES}

1. Fu, Y.; Elsenbaumer, R. L.; Chem. Mater. 1994, 6, 671.

2. Huang, W. -S.; MacDiarmid, A. G.; Epstein, A. J.; J. Chem. Soc. Chem. Commun. 1987, 1784.

3. Nalwa, H. S. (Ed.), Handbook of Organic Conductive Molecules and Polymers, vol.2, John Wiley \& Sons, New York, 1997.

4. Ruiz-Hitzky, E.; Anal. Quím. Int. Ed. 1997, 93, 197.

5. Ruiz-Hitzky, E.; Adv. Mater. 1993, 5, 334

6. Ohtsuka, K.; Chem. Mater. 1997, 9, 2039.

7. Okuno, S.; Matsubayashi, G. -E.; Inorg. Chim. Acta, 1995, 233, 173.

8. Maia, D. J.; Alves, O. L.; De Paoli, M. -A.; Synth. Met. 1997, 90, 37

9. Bonnet, B.; El Mejjad, R.; Herzog, M. -H.; Jones, D. J.; Rozière, J.; J. Mater. Science Forum 1992, 91-93, 177.

10. Rosenthal, G. L.; Caruzo, J.; Stone, S. G.; Polyhedron 1994, 13, 1311 .

11. Liu, Y. -J.; Kanatzidis, M. G.; Inorg. Chem. 1993, 32, 2989.

12. Kanatzidis, M .G.; Bissessur, R.; DeGroot, D. C.; Shindler, J. L.; Kannewurf, C. R.; Chem. Mater. 1993, 5, 595.

13. De Stefanis, A.; Foglia, S.; Tomlinson, A. A. G.; J. Mater. Chem. 1995, 5, 475.

14. Liu, Y. -J.; Degroot, D. C.; Shindler, J. L.; Kannewurf, C. R.; Kanatzidis, M. G.; J. Chem. Soc. Chem. Commun. 1993, 593.

15. Bissessur, R.; DeGroot, D. C.; Shindler, J. L.; Kannewurf, C. R.; Kanatzidis, M. G.; J. Chem. Soc. Chem. Commun. 1993, 688.

16. Tudor, J.; Willington, L.; O'Hare, D.; Royan, B.; J. Chem. Soc. Chem. Commun. 1996, 2031

17. Guliants, V. V.; Benziger, J. B.; Sundaresan, S.; J. Catalysis 1995, 156, 298.

18. Liu, Y. -J.; DeGroot, D. C.; Shindler, J. L.; Kannewurf, C. R.; Kanatzidis, M. G.; Adv. Mater. 1993, 5, 369.

19. Ouahab, L.; Chem. Mater. 1997, 9, 1909.

20. Schöllhorn, R.; Chem. Mater. 1996, 8, 1747.

21. Sayari, A.; Karra, V. R.; Reddy, J. S.; Moudrakovski, I. L.; J. Chem. Soc. Chem. Commun. 1996, 411.

22. Peralta-Zamora, P.; Moraes, S. G.; Reynes, J.; Durán, N.; Polymer Bull. 1996, 37, 531.

23. Huang, W. -S.; MacDiarmid, A. G.; Polymer 1994, 34, 1833.

24. Rao, C. N. R.; J. Chem. Soc. Chem. Commun 1996, 2217.

25. Gates, B. C., Catalytic Chemistry, John Wiley \& Sons, New York, 1992.

26. Durán, N., Espósito, E., Rodrigues, J. J.; Photochem. Photobiol. 1991, 62, 269.

27. Durán, N.; Espósito, E.; Inocentini-Mei, L. H.; Biodegradation 1994, 5, 13.

28. Farias, R. F. de; Souza, J. M. de; Melo, J. V. de; Airoldi, C.; J. Colloid Interf. Sci. 1999, 212, 123.

29. Farias, R. F. de; Souza, J. M. de; Melo, J. V. de; Airoldi, C.; J. Colloid Interf. Sci. 2000, in press.

30. Geniès, E. M.; Boyle, A.; Laokowski, M.; Tsintavis, C.; Synth. Met. 1990, 36, 139.

31. Kulszewicz-Bajer, I.; Pron, A.; Abramowicz, J.; Jeandey, C.; Oddou, J. -L.; Sobczak, J. W.; Chem. Mater. 1999, 11, 552.

32. Chan, H. S. O.; Teo, M. Y. B.; Khor, E.; Lim, C. N.; J. Thermal Anal. 1989, 35, 765.

33. Neoh, K. G.; Kang, E. T.; Tan, K. L.; Thermochim. Acta 1990, 171, 279.

34. Farias, R. F. de; Airoldi, C.; J. Thermal Anal. 1998, 53, 751.

35. Farias, R. F. de; Nunes, L. M.; Airoldi, C.; J. Thermal Anal. 2000, in press. 